\title{
Quantitative Characterization of the Aqueous Fraction from Hydrothermal Liquefaction of Algae
}

Balakrishna Maddi, ${ }^{\mathrm{a}}$ Ellen Panisko, ${ }^{\mathrm{a}}$ Thomas Wietsma, ${ }^{\mathrm{a}}$ Teresa Lemmon, ${ }^{\mathrm{a}}$ Marie Swita, ${ }^{\mathrm{a}}$ Karl Albrecht, ${ }^{\mathrm{a}}$ and Daniel Howe ${ }^{\mathrm{a}^{*}}$

${ }^{a}$ Pacific Northwest National Laboratory, P.O. Box 999, Richland, WA 99352, USA

*Corresponding author

Daniel Howe

Development Engineer

Pacific Northwest National Laboratory, P.O. Box 99352, Richland, WA 99352, USA

e-mail: Daniel.howe@pnnl.gov

Phone: 1-509-372-4355

Fax: 1-509-372-1861 


\begin{abstract}
$\underline{\text { Abstract }}$
The aqueous fraction generated from hydrothermal liquefaction (HTL) of algae contains approximately 20 to $35 \%$ of the total carbon present in the algal feed. Hence, this aqueous fraction can be utilized to produce liquid fuels and/or specialty chemicals for economic sustainability of HTL on an industrial scale. In this study, aqueous fractions produced from HTL of freshwater and saline-water algal cultures were analyzed using a wide variety of analytical instruments to determine their compositional characteristics. Organic chemical compounds present in eight aqueous fractions were identified using two-dimensional gas chromatography equipped with time-of-flight mass spectrometry. Identified compounds include organic acids, nitrogen compounds and aldehydes/ketones. Conventional gas chromatography and liquid chromatography methods were utilized to quantify the identified compounds. Inorganic species in the aqueous stream from HTL of algae also were quantified using ion chromatography and inductively coupled plasma optical emission spectroscopy. The concentrations of organic chemical compounds and inorganic species are reported. The amount quantified carbon ranged from 45 to $72 \%$ of the total carbon in the aqueous fractions.
\end{abstract}

Key words: Hydrothermal liquefaction, algae, biofuels, thermochemical conversions, wastewater analysis 


\section{Introduction}

The increasing demand for and unsustainable nature of petrochemical transportation fuels continues to raise concerns about the environmental, political, and economic impacts associated with their use [1]. According to recent reports, $70 \%$ of all the petroleum consumed by the United States was used to produce liquid transportation fuels [2]. Given these concerns, the use of renewable biomass feedstocks to produce infrastructure compatible liquid fuels has witnessed serious consideration [3]. Biomass, broadly defined as organic matter derived from living organisms, can be broken into two primary categories based on their compositional characteristics: 1) lignocellulosic and 2) non-lignocellulosic. Lignocellulosic biomass includes wood, forest and agricultural residues, as well as dedicated energy crops. Lignocellulose is composed primarily of carbohydrates, such as cellulose and hemicellulose, and lignin [4]. Nonlignocellulosic biomass, such as algae, oilseeds, and some food processing residues, are composed primarily of proteins, carbohydrates, lipids, and oils [5]. It is projected that lignocellulosic materials can satisfy $30 \%$ of the current liquid fuel demands in terms of gasoline, diesel, and jet fuel if they are sustainably cultivated and harvested $[6,7]$. While $30 \%$ is significant, the use of non-lignocellulosic feedstocks will be necessary to meet the growing demand for renewable fuels. Aquatic microorganisms such as microalgae are considered to be a significant feedstock for the production of liquid fuels to complement those produced by lignocellulosic feedstocks $[8,9]$.

Algal feedstocks have a number of advantages over traditional lignocellulosic feedstocks, including high yields on an area basis [9]; utilization of low-quality, brackish, or sea water [10]; and the ability to concentrate high energy triglycerides to yield an energy-dense material. Using algae in thermochemical conversion processes that generate liquid fuels has become a cornerstone of biofuels research $[10,11]$. However, due to their high water content, they are not particularly well suited for a number of direct and indirect liquefaction processes (e.g., fast pyrolysis and gasification) that require a dry feedstock. One technology that can not only tolerate but actually requires high water content is hydrothermal liquefaction (HTL). 
HTL is a direct liquefaction process capable of utilizing the water naturally associated with algae. It also is considered a viable technology because of its inherent scalability [11,12] and high oil and carbon yields. During HTL processing, the biomass is mixed with water to produce slurry that is then pumped into a plug flow reactor. The reactor is operated in the condensed phase at high pressure (10 to 25 $\mathrm{MPa})$ and moderate temperature $\left(280\right.$ to $\left.370^{\circ} \mathrm{C}\right)$ with a residence time in the range of 5 to $60 \mathrm{~min}$ [13]. The product stream from continuous-flow HTL processing consists of an organic oil fraction, referred to as bio-crude, solids that include ash and a small amount of char; non-condensable gasses such as $\mathrm{CO}_{2}$, $\mathrm{CH}_{4}$, and $\mathrm{H}_{2}$ : and a distinct aqueous fraction that separates by gravity from the oil fraction. The bio-crude fraction is then upgraded via catalytic hydroprocessing (also referred to as hydrotreatment) in a process that includes catalytic hydrodeoxygenation and hydrocracking [14]. Upgrading of the bio-crude is necessary to decrease the oxygen and other heteroatom content to make a product compatible with petroleum refinery operations that produce a finished fuel. Thermally stable HTL bio-crude can be hydrotreated in a single step, which is a distinct advantage over bio-oils produced by fast pyrolysis of lignocellulosic feedstocks $[15,16]$.

Although direct liquefaction processes have been extensively studied, the focus of these studies is primarily on the quality and quantity of the oil produced [10-12]. The aqueous fraction produced during HTL is considered a byproduct stream, and as such, it is generally qualitatively characterized for major functional groups rather than quantitatively analyzed for specific compounds $[17,18]$. This lack of data was highlighted in a report where a key gap in the existing water footprint analysis was attributed to limited data availability, and "In particular, information on wastewater characterization of the new developing processes is limited in the public domain." [19] Hundreds of compounds have been identified in the HTL aqueous stream with the predominant fractions consisting of low molecular weight oxygenates (including acids, alcohols, ketones, and aldehydes) formed by the degradation of carbohydrates and lipids, and nitrogen heterocyclics (including pyrroles, pyridines, pyrazines, and imidazoles) derived from protein decomposition [20]. Quantitative characterization of the organic compounds has been performed on the 
HTL aqueous byproduct, but only using lignocellulosic feedstocks [21]. In addition to organic compounds, the aqueous byproduct generated from HTL of algae also includes inorganic species present in the aqueous sources (e.g., salts in sea water) and those that were added to the media for algal growth. Because nutrient recycle, especially nitrogen and phosphorous, improves the overall sustainability of an algae bio-refinery, these minerals have to be recovered from aqueous streams for reuse in algal growth $[22]$.

The aqueous phase contains approximately 20 to $35 \%$ of the total carbon present in the algae, so to enhance the economic feasibility of HTL systems and minimize environmental impact, this byproduct must be treated for discharge or reuse, used in anaerobic digesters to produce methane, or catalytically processed to convert the carbon into useful chemicals or fuels. Catalytic hydrothermal gasification (CHG) is one technology that has shown great potential for converting the organic compounds present in the aqueous phase to a high energy content biogas consisting of $\mathrm{H}_{2}, \mathrm{CH}_{4}, \mathrm{CO}$, and $\mathrm{CO}_{2}$ [23]. Use of $\mathrm{CHG}$ has been shown to reduce the chemical oxygen demand of an aqueous fraction from the HTL of algae by 98.8 to $99.8 \%$ [11]. Research also is being conducted to develop processes capable of generating liquid fuel range hydrocarbons and hydrogen by upgrading and reforming the carbon present in the aqueous phase [24]. Given the catalytic nature of these processes, maximizing their efficiencies will require characterization data identifying the exact compounds present as well as their quantity.

To enable further development of aqueous-phase catalytic upgrading and reforming processes, develop more accurate techno-economic analyses and HTL process models, and fill an acknowledged gap in the available literature, aqueous samples from the HTL of four freshwater and four seawater algae were quantitatively characterized using gas chromatography (GC), liquid chromatography (LC), inductively coupled plasma spectrometry, ion chromatography, chemical oxygen demand, ammonia $\left(\mathrm{NH}_{3}\right)$, and total carbon analysis.

\section{Materials and Methods}




\subsection{Feedstocks}

The algal feedstocks used in this study were either freshwater or saltwater varieties obtained from different suppliers. FW1 and FW2 were supplied by BioProcess Algae, LLC. They are both of the genus Chlorella and were harvested in 2015. FW1 was grown heterotrophically to produce a high lipid content, while the FW2 was grown phototrophically and produced a "standard" lipid concentration [25]. FW3 was Scenedesmus obliquus, grown at the University of Arizona in 2015. FW4 was of the genus Chlorella, and also was grown at the University of Arizona in 2015. All of the saltwater algae studied were of the genus Tetraselmis, supplied by Cellana, LLC, and grown in 2013 as part of the National Alliance for Advanced Biofuels and Bio-products [26].

\subsection{Hydrothermal liquefaction of algal feedstocks}

HTL was conducted on four freshwater algae and four saline-water algae cultures at $350^{\circ} \mathrm{C}$ and 20.7 MPa (3000 psi) using a continuous-flow, bench-scale system described previously in the literature $[11,12,21]$. Table 1 shows the processing conditions used to generate each individual sample. A higher space velocity was used for SW4 to investigate the effects of residence time on oil yields and quality. A block diagram outlining this process is shown in Figure 1. Chemical oxygen demand and $\mathrm{NH}_{3}$ content were determined using an $\mathrm{HACH}$ (Loveland, $\mathrm{CO}$ ) reagent-kit and spectrophotometry.

\section{[Insert Figure 1 Here]}

\section{[Insert Table 1 Here]}

\subsection{Inductively coupled plasma optical emission spectrometer analysis}

Inorganic (cation) analysis was performed on a Perkin Elmer (Waltham, MA) Optima 7300DV inductively coupled plasma optical emission spectrometer with a Meinhard nebulizer, glass cyclonic spray chamber, and 2.0-mm alumina injector. The instrument software version was WinLab32 version 4.0. Calibration standards were prepared from certified standards, and verified with certified standards 
from a second source. Calibration standards and quality control standards were analyzed daily. Samples were filtered and diluted in deionized water as necessary to be within the calibration range. The list of elements analyzed were: Ag (328.068), Al (396.153), As (188.979), Ba (233.527), Ca (317.933), Co (228.616), Cr (267.716), Cu (327.393), Fe (238.204), K (766.490), Mg (285.213), Mn (257.610), Na (589.592), Ni (231.604), P (178.221), Pb (220.353), Re (197.248), Sr (421.552), V (310.230), Y (371.029), Zn (206.200), Mo (202.031), Si (251.611), Ti (334.940), W (207.912), Au (267.595), Pd (340.458), Pt (265.945), Rh (343.489), Ru (240.272), S (180.669), Sn (189.927), and Zr (343.823). The numbers in parentheses are the wavelengths in nano-meters used to quantify that particular metal.

\subsection{Ion chromatography analysis}

Samples were analyzed using a Dionex-3000 (Sunnyvale, CA) Liquid Chromatography system equipped with a conductivity detector. A Dionex IonPac AS11 hydrocracking column was used and maintained at $30^{\circ} \mathrm{C}$. Data were collected at $5 \mathrm{~Hz}$ with a cell temperature of $35^{\circ} \mathrm{C}$. Calibration standards were obtained from High Purity Standards (Charleston, SC) (Multi-Element IC Std I Solution A, Catalog number: IC-1) and standard curves was obtained using a two-point calibration curve, $100 \mu \mathrm{g} \mathrm{mL}{ }^{-1}$, and 10

$\mu \mathrm{g} \mathrm{mL} \mathrm{m}^{-1}$ for each individual anion. Another set of standards was purchased from VHG Labs (Manchester, $\mathrm{NH}$ (Multi-Anion Standard 1 in $\mathrm{H}_{2} \mathrm{O}$, Catalog number: VHG-ICM1-100) to validate calibration curves.

\subsection{Carbon and inorganic carbon analysis}

Total carbon, total nitrogen, and total inorganic carbon analysis was performed using a Shimadzu (Columbia, MD) TOC-5000A TC analyzer equipped with a Shimadzu ASI-5000A auto-sampler and a non-dispersive infrared detector. Quantification ranges for total carbon were $500 \mathrm{ppb}$ to $4000 \mathrm{ppm}$, and for inorganic carbon ranged from $500 \mathrm{ppb}$ to $5000 \mathrm{ppm}$. All samples were analyzed with six replicates and the results were averaged. Injections of $21 \mu \mathrm{L}$ were analyzed in the TC using catalytically aided combustion oxidation at $680^{\circ} \mathrm{C}$ to produce $\mathrm{CO}_{2}$ which was measured with a non-dispersive infrared detector. Inorganic carbon was measured separately by digesting the sample with phosphoric acid and 
measuring the resultant $\mathrm{CO}_{2}$. Nitrogen was separately determined by converting it into NO which was measured using a chemiluminescence detector.

2.6 Qualitative characterization using two-dimensional gas chromatography with time-of-flight mass spectrometry $(G C \times G C-T O F-M S)$

All the aqueous fractions of algal bio-crude samples were characterized using a LECO (St. Joseph, MI) Pegasus 4D ${ }^{\mathrm{TM}}$ instrument. This instrument includes an Agilent (Santa Clara, CA) 7890 GC equipped with quad-jet, dual stage cooling-based modulator and time-of-flight (TOF) mass spectrometer (MS). The primary column was a Restek (Bellefonte, PA) stabilwax $(60 \mathrm{~m} \times 0.25 \mathrm{~mm} \times 0.5 \mu \mathrm{m}$ film thickness) capillary column and the secondary column was an Rxi $5 \mathrm{MS}(3.3 \mathrm{~m} \times 0.25 \mathrm{~mm} \times 0.5 \mu \mathrm{m}$ film thickness). Modulation occurs on the secondary column.

For each sample, $0.5 \mu \mathrm{L}$ was injected into the $\mathrm{GC}$ at an injector temperature of $260^{\circ} \mathrm{C}$. The $\mathrm{GC}$ primary column was ramped from $40^{\circ} \mathrm{C}$ to $260^{\circ} \mathrm{C}$ at $5^{\circ} \mathrm{C} \min ^{-1}$ and held at $260^{\circ} \mathrm{C}$ for $5 \mathrm{~min}$. A modulation period of $6 \mathrm{~s}$ was used with $1.2 \mathrm{~s}$ of hot pulse and $1.8 \mathrm{~s}$ of cold pulse. The detector voltage during data

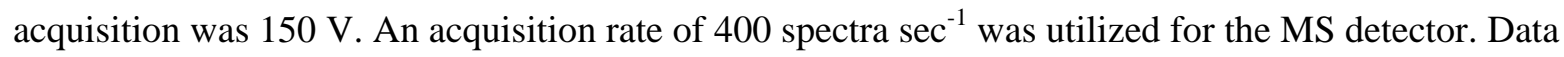
processing was performed using ChromaTOF 4.50. Chemical compounds were identified using the NIST2008 mass spectral database. This method was described in detail in the literature [27]. In addition to identification, the GC $\times$ GC - TOF-MS was also used to quantify N-methyl succinimide and 3-pyrindol utilizing the nitrogen standard and procedure described under the "Gas chromatography analysis" section. The $\mathrm{R}^{2}$ value of calibration curves of $\mathrm{N}$-methyl-succinimide and 3-pyrindol were $>0.95$.

\subsection{Gas chromatography analysis}

Preliminary two-dimensional GC with TOF-MS was performed on all the aqueous fractions generated from HTL of algae to identify the chemical compounds present. Prepared or purchased standards were used for quantitative characterization. A custom commercial calibration mixture was purchased from Restek Corporation containing acetone, ethanol, 2-pentanone, 2-butanone, 3-pentanone, 
cyclopenatanone, and pyridine at $0.5 \%$ (weight/weight) in water. Separate standards containing Ncompounds were prepared. These standards included pyrazine, acetamide, 2-pyrrolidinenone, Nmethylsuccinimide, 3-pyrindol, and $\mathrm{N}$-(hydroxyethyl) succinimide, each at $1.0 \mathrm{wt} \%$ in water. Each solution was diluted with water gravimetrically to produce eight-point calibration ranges from approximately $0.005 \%$ to $1.0 \%$ (weight/weight). Quadruplicate measurements of all samples and each standard mixture at every calibration level by GC/MS and GC/flame ionization detection (FID) were performed in a blocked randomized experimental design to control for instrument performance. This procedure follows NIST recommendations for statistical calibration (NIST/SEMATECH e-Handbook of Statistical Methods, http://itl.nist.gov/div898/handbook/, Chapter 2, Section 2.3.6.2 Data Collection). Calibration and testing are coupled in one design to maintain statistical balance, avoid confounding of treatment effects estimates, improve the estimation of variance components, and simplify the statistical analysis.

An Agilent 7890 GC with a 5875 MSD was configured with dual columns, both of which were fused silica capillary columns with a stationary phase of 5\%-phenyl-methylpolysiloxane (HP-5MS, Agilent J\&W), $30 \mathrm{~m}$ long, $0.25 \mathrm{~mm}$ inner diameter, and $0.25 \mu \mathrm{m}$ film thickness. For both the GC/MS and GC/FID methods, a $0.5-\mu 1$ volume of each sample was injected at an initial oven temperature of $40^{\circ} \mathrm{C}$. The temperature then was ramped at $10^{\circ} \mathrm{C} / \mathrm{min}$ to $280^{\circ} \mathrm{C}$. The MS was configured in electron impact with an electron multiplier voltage of 1071 . The MS source was set at $230^{\circ} \mathrm{C}$, and the quadropole was set at $150^{\circ} \mathrm{C}$. Following identification of the calibration compounds, quantitation by GC/FID was performed utilizing peak areas obtained from the MSD ChemStation software after visual alignment of chromatograms. The average $\mathrm{R}^{2}$ value from the linear regression of calibrations utilized to generate data reported in this paper was 0.98 . If there was an issue with a co-elutor or peak shape, quantitation by GC/MS was performed using peak areas of extracted ion chromatograms of a characteristic ion for that standard compound. We have assumed that chemical compounds and their alkyl derivatives have similar response factors. Hence, alkyl derivatives of a compound were quantified using the calibration curve of 
the parent compound. For example, methyl-pyrazine, dimethyl-pyrazine, and ethyl-pyrazine were quantified using the calibration curve of pyrazine. As mentioned in section 2.2, because of the poor linear correlation observed on the conventional GC, N-methyl-succinimide and 3-pyrindol were quantified by the $\mathrm{GC} \times \mathrm{GC}-\mathrm{TOF}-\mathrm{MS}$ instrument.

\subsection{Liquid chromatography analysis}

An Agilent (Santa Clara, CA) 1100 Liquid Chromatography system equipped with a refractive index detector was used to quantify the organic acids present in the aqueous samples. A custom commercial calibration mixture containing acetic acid, propanoic acid, and butanoic acid at $1.0 \%$ (weight/weight) in water was purchased from Restek Corporation. The organic acid solution was diluted with water gravimetrically to produce a six-point calibration range from approximately $0.05 \%$ to $1.0 \%$ (weight/weight). Quadruplicate measurements of all samples and standard mixtures at each calibration level were performed in a blocked randomized experimental design to control for instrument performance. A $10 \mu \mathrm{l}$ injection of each sample was made onto an Aminex HPX-87H $\left(7.8\right.$ x $\left.300 \mathrm{~mm}^{2}\right)$ ion exclusion column, (Bio-Rad), equipped with a guard column $\left(4.6 \times 30 \mathrm{~mm}^{2}\right)$, using an Agilent $1100 \mathrm{LC}$ system. The column was eluted isocratically with $0.005 \mathrm{M}$ sulfuric acid through a refractive index detector. Quantification was performed utilizing peak areas obtained from the ChemStation software after integration of the chromatograms. The average $\mathrm{R}^{2}$ value from the linear regression of calibrations utilized to generate data reported in this publication was 0.98 , with a standard deviation of 0.001 .

\section{Results and Discussion}

Overall mass and carbon balances of the HTL process indicate that the aqueous streams generated contain a significant fraction of the carbon fed to the system (see Table 1). The weight percentage of feed carbon in the aqueous byproduct of HTL for both saline-water and freshwater algal slurries is in the range of 10 to $35 \%$. The higher space velocity used in the SW4 experiment resulted in the highest fraction of biogenic carbon found in the aqueous phase and the lowest oil yield of the saltwater algae experiments. 
The aqueous byproduct generated from HTL of both saline-water and freshwater algae slurries (except for FW1) are mildly basic (pH 7 to 9). The acidic aqueous byproduct from FW1 was due to the very unique composition of algae grown under heterotrophically stressed conditions; namely its high lipid content and low protein [25]. These values differ from $\mathrm{pHs}$ reported for the aqueous stream collected from HTL of lignocellulosic biomass (i.e., $\mathrm{pH} 4$ to 5.5) [21]. The basic nature of the aqueous phase obtained from HTL of algae is likely due to the presence of $\mathrm{NH}_{3}$ and nitrogenous compounds. This assumption is supported by a recent study that reported a basic $\mathrm{pH}$ of the aqueous byproduct generated from HTL of algae and correlated it to high concentrations of $\mathrm{NH}_{3}$ and nitrogenous compounds [28]. These nitrogenous compounds could be produced from degradation of proteins and their amino acid components during HTL $[5,29,30]$. In addition to nitrogenous compounds, this aqueous stream may also contain organic acids (such as acetic acid, propionic acid, and butanoic acid) and oxygenates produced from degradation of carbohydrates present in algal feedstocks [21]. The acidic nature of the FW1 sample may be due to low amounts or the absence of nitrogenous compounds or an increase in carbohydrate breakdown during processing (the FW1 slurry contained had a high lipid content and very little nitrogen).

GC $\times$ GC - TOF-MS was used for qualitative analysis to improve resolution (or separation of chemical compounds in a sample), peak capacity (i.e., number of resolved peaks), signal-to-noise ratio (for identification of chemical compounds with high confidence), and to avoid co-elution of chemical compounds [31]. A three-dimensional (3D) plot of the total ion chromatogram obtained for the HTL aqueous byproduct of the SW4 algal culture analyzed with a column combination of polar $\times$ non-polar is shown in Figure 2 (3D plots of all other samples are shown in supplementary data, Figures S1 through S7). Retention times (both primary and secondary) and similarity values of identified compounds in the SW4 aqueous stream are presented in Table 2. Organic acids (including acetic acid, propanoic acid, and butanoic acid), nitrogen-containing compounds (such as pyridine, pyrazine, acetamides, 2-piperidinone, 2-pyrrolidinone, succinimide, and their alkyl derivatives) and trace amounts (low-intensity peaks) of oxygenates (such as cyclopenatanone, 2-butanone, 2-pentanone, and dianhydromannitol) were observed 
in all aqueous samples [32]. Oxygenates and organic acids could be formed from thermal degradation of the algae carbohydrate fraction during HTL [33].

\section{[Insert Figure 2 Here]}

\section{[Insert Table 2 Here]}

The aqueous fraction from HTL of FW2, FW3, FW4, and all saline-water samples contain dissolved $\mathrm{CO}_{2}$ and/or $\mathrm{CO}_{2}-\mathrm{NH}_{3}$ salts such as ammonium carbamate. Ammonium carbamate is a product from the reaction of $\mathrm{CO}_{2}$ and $\mathrm{NH}_{3}$ [34] that may occur during HTL. The GC mass spectrum of ammonium carbamate is similar to that of $\mathrm{CO}_{2}$, and as a result, MS could not distinguish between these two due to an equal similarity score (spectra shown in Figure S8 and S9; similarity score of $\mathrm{CO}_{2}$ is 997 and ammonium carbamate 999). The pHs of these samples are in the range of 7.5 to 9.0 , which is due to the presence of high amounts of $\mathrm{NH}_{3}$ and ammonium carbamate. Alternatively, the observed peak may be $\mathrm{CO}_{2}$ produced from pyrolytic degradation of high-molecular weight compounds, especially nitrogenous compounds (proteins) in the GC injector (which has similar conditions to those of a pyrolysis reactor). Previous studies have reported the presence of these compounds in the aqueous byproduct generated from HTL of algae [20]. Inorganic carbon, which is present is every aqueous HTL stream analyzed, can also produce $\mathrm{CO}_{2}$ but would require a catalyst such as phosphoric acid. The aqueous phase collected from HTL of the FW1 sample did not contain $\mathrm{NH}_{3}$, dissolved $\mathrm{CO}_{2}$ and/or ammonium carbamate (see 3D plot of aqueous stream from FW1 sample; Figure S4), which may result in the low $\mathrm{pH}$.

Because the $\mathrm{GC} \times \mathrm{GC}-\mathrm{TOF}-\mathrm{MS}$ method has a programmable temperature limit of $250^{\circ} \mathrm{C}$, longchain fatty acids (from degradation of triglycerides) and high-molecular weight nitrogenous compounds cannot be identified. Therefore, samples also were analyzed using conventional GC-MS. The total ion chromatogram of the aqueous fraction from HTL of the SW4 algal slurry is shown in Figure S10. Highmolecular weight nitrogenous compounds, presumably the result of protein degradation during HTL, were 
identified (Figure S10). Because standards for these compounds are not commercially available, quantification of these compounds was not pursued.

Identified chemical compounds, both oxygenate and nitrogenous compounds, in the aqueous stream from the HTL of algae have a wide variety of applications. Pyridine, pyrazine, and their alkyl derivatives are intermediate chemicals for the production of agrochemicals and drugs [35, 36], and are widely used as solvents in homogenous catalysis [37, 38]. N-methyl succinimide and N-ethyl succinimide also have a wide variety of applications including detergents [39], clinical drugs [40, 41], fuel additives, and lubricating oil additives [39]. The organic acids present in these aqueous byproducts can be catalytically converted to high-value polymeric precursors (i.e., ketones or esters) [42]. Hence, the amounts of these chemical compounds present should be determined to estimate or assess both economic and technological feasibility for separation from the aqueous stream or catalytic conversion in the aqueous phase.

Prior to quantifying the aqueous byproduct collected from HTL of algal cultures, total carbon and inorganic content was determined (Figure 3). The total and inorganic carbon contents of the aqueous byproduct generated during HTL of algae cultures are in the range of 1.4 to $3.4 \mathrm{wt} \%$ and 0.04 to $0.6 \mathrm{wt} \%$, respectively.

\section{[Insert Figure 3 Here]}

Based on qualitative analysis, standards were purchased or prepared for quantification using conventional GC-FID and LC analysis. Because the spectra for N-methyl-succinimide and 3-pyrindol overlap in the chromatogram and have poor linear correlation when analyzed using conventional GC-MS, we quantified these two compounds using GC $\times$ GC - TOF-MS. Amounts of each of the chemical compounds present in all of the aqueous byproduct generated from HTL of both saline-water and freshwater algal slurries are shown in Table 3. We observed trace amounts of nitrogenous compounds and 
high concentrations of organic acids. This may have contributed to the low $\mathrm{pH}$ of the FW1 sample. Nitrogen containing compounds, $\mathrm{CO}_{2}$, and $\mathrm{CO}_{2}-\mathrm{NH}_{3}$ salts were present in all other samples, which may have contributed to the high $\mathrm{pH}$ in samples other than FW1. Therefore, our results support earlier reports that the basic $\mathrm{pH}$ of HTL aqueous fractions correlates with the presence of basic nitrogenous compounds [25].

\section{[Insert Table 3 Here]}

The total amount of quantified organic carbon compared to the total organic carbon for each sample is shown in Figure 4. The quantified carbon (except for FW1) is in the range of 45 to $72 \%$ of the total organic carbon. This range is lower than the values reported for the aqueous byproduct from HTL of lignocellulosic feedstocks [21] because dissolved $\mathrm{CO}_{2}, \mathrm{CO}_{2}-\mathrm{NH}_{3}$ salts, high-molecular-weight nitrogenous compounds, and long-chain fatty acids were not quantified. For the aqueous fraction from HTL of FW1 algae, most compounds identified were below the quantification limit. Glycerol was identified in the aqueous fraction from HTL of FW1 algae but was not considered for quantification (see Figure S4). Hence, the amount of quantified carbon is low for the aqueous fraction from HTL of FW1 algae compared to the other HTL aqueous samples.

\section{[Insert Figure 4 Here]}

The total amount of quantified nitrogen compared to the total nitrogen for each sample is shown in Figure 5. The quantified nitrogen (except for FW1) is in the range of 41 to $85 \%$ of the total nitrogen. Ammonia was quantified separately using a commercially available assay. Unquantified nitrogen in the aqueous sample could have originated from high-molecular-weight oligomers of algal proteins produced during HTL (the chemical structures and mass spectra of two oligomers are shown in Figures S11 and S12).

\section{[Insert Figure 5 Here]}


Downstream processing of these aqueous byproducts involves catalytic process such as $\mathrm{CHG}$, catalytic condensed-phase reactions, and enzymatic biological processes. Because catalytic processes are very sensitive to metal atoms and anions present in these aqueous byproducts, the weight fraction of inorganic species present were determined and are tabulated in Tables 4 and 5. Trace amounts (i.e., $<0.00008$ wt\%) of Ag, As, Ba, Cd, Co, Cr, Cu, Fe, Mn, Pb, Re, Y, Zn, Mo, Ti, W, Au, Pd, Pt, Rh, Sn, Zr, and Ru were observed in all samples. The aqueous stream generated from HTL of saline-water algae contains higher amounts of $\mathrm{Na}, \mathrm{Mg}, \mathrm{K}, \mathrm{Ca}$, and chloride than that of freshwater algae cultures, indicating the presence of chloride salts of alkali and alkaline earth metals. Because alkali and alkaline earth metals promote the production of hydrogen during CHG of coal, algal, and lignocellulosic biomass [43-47], these metals may act as promoters for $\mathrm{CHG}$ at high temperatures. However, alkali and alkaline earth metals may interfere with other catalytic materials used in the downstream processes, especially catalytic condensed-phase reactions

\section{[Insert Table 4 Here]}

\section{[Insert Table 5 Here]}

Compounds containing $\mathrm{Si}, \mathrm{P}$, and $\mathrm{S}$ are added to the media for algal growth. Hence, these minerals are seen in the aqueous byproduct from HTL of algae and are in higher concentrations than that generated from lignocellulosic feedstocks. Presence of $\mathrm{S}$ in the aqueous stream from HTL of algae also may be produced from hydrolysis of S-containing proteins during HTL. Sulfur present in the aqueous byproduct from HTL of algae may poison catalysts used in downstream processes, especially if noble metals are used in the catalysts. Because inorganic species present in the aqueous byproduct interfere with downstream catalytic processes, these nutrients should be recovered for reuse in algal growth, which would improve the overall sustainability of the algal bio-refinery.

\section{Conclusions}


In this study, organic and inorganic species present in aqueous byproducts from HTL of salinewater and freshwater algae were identified and quantified. The main organic chemical compounds identified and quantified were acetic acid, propanoic acid, pyridine, acetone, ethanol, pyrazine, alkylpyrazine, acetamide, $\mathrm{N}$-alkyl-acetamide, $\mathrm{N}$-methylsuccinimide, $\mathrm{N}$-ethylsuccinimide, 2-pyrrolidinone, alkyl-2-pyrrolidinone, 2-piperidinone, 3-pyrindol, and alkyl-3-pyrindol. Nitrogenous compounds such as pyridine, alkyl-pyrazine, $\mathrm{N}$-alkyl-succinimide, and 2-pyrrolidinone are high-value compounds that have a wide variety of applications. Chlorides of alkali and alkaline earth metal present in the aqueous byproduct from HTL of saline-water algae catalyze the hydrothermal gasification process, but may interfere with other catalytic processes. Information obtained from this quantitative analysis will inform designs of processes used for downstream treatment of HTL aqueous fractions. These designs might include a stable and active catalyst for $\mathrm{CHG}$ or catalytic conversion in the condensed aqueous phase.

\section{Acknowledgement}

This manuscript was written by staff members at Pacific Northwest National Laboratory (PNNL), which is operated by Battelle for the U.S. Department of Energy under Contract No. DE-AC0576RL01830. The United States Government retains and the publisher, by accepting the article for publication, acknowledges that the United States Government retains a non-exclusive, paid-up, irrevocable, world-wide license to publish or reproduce the published form of this manuscript, or allow others to do so, for United States Government purposes.

The authors would like to thank Andrew Schmidt at PNNL for supplying the aqueous byproduct generated from HTL of saline-water and freshwater algae.

\section{References Cited}

[1] Huber GW, Iborra S, Corma A. Synthesis of Transportation Fuels from Biomass: Chemistry, Catalysts, and Engineering. Chemical Reviews. 2006;106(9):4044-98. 
[2] EIA. Annual Energy Outlook 2013 with Projections to 2040. Washington, DC: Department of Energy - U.S. Energy Information Administration; 2013.

[3] Logan BE. Extracting Hydrogen and Electricity from Renewable Resources: a roadmap for establishing sustainable processes. Environmental Science \& Technology. 2004;38(9):160A-7A.

[4] Sjostrom E. Wood Chemistry: Fundamentals and Applications. 2nd ed. San Diego: Academic Press; 1993.

[5] Maddi B, Viamajala S, Varanasi S. Comparative study of pyrolysis of algal biomass from natural lake blooms with lignocellulosic biomass. Bioresource Technology. 2011;102(23):11018-26.

[6] Kim S, Dale BE. Global potential bioethanol production from wasted crops and crop residues. Biomass and Bioenergy. 2004;26(4):361-75.

[7] von Blottnitz H, Curran MA. A review of assessments conducted on bio-ethanol as a transportation fuel from a net energy, greenhouse gas, and environmental life cycle perspective. Journal of Cleaner Production. 2007;15(7):607-19.

[8] Hu Q, Sommerfeld M, Jarvis E, Ghirardi M, Posewitz M, Seibert M, et al. Microalgal triacylglycerols as feedstocks for biofuel production: perspectives and advances. The Plant Journal. 2008;54(4):621-39. [9] Georgianna DR, Mayfield SP. Exploiting diversity and synthetic biology for the production of algal biofuels. Nature. 2012;488(7411):329-35.

[10] Amaro HM, Guedes AC, Malcata FX. Advances and perspectives in using microalgae to produce biodiesel. Applied Energy. 2011;88(10):3402-10.

[11] Elliott DC, Hart TR, Schmidt AJ, Neuenschwander GG, Rotness LJ, Olarte MV, et al. Process development for hydrothermal liquefaction of algae feedstocks in a continuous-flow reactor. Algal Research. 2013;2(4):445-54.

[12] Elliott DC, Biller P, Ross AB, Schmidt AJ, Jones SB. Hydrothermal liquefaction of biomass: Developments from batch to continuous process. Bioresource Technology. 2015;178(0):147-56.

[13] Behrendt F, Neubauer Y, Oevermann M, Wilmes B, Zobel N. Direct Liquefaction of Biomass. Chemical Engineering \& Technology. 2008;31(5):667-77. 
[14] Zacher AH, Olarte MV, Santosa DM, Elliott DC, Jones SB. A review and perspective of recent biooil hydrotreating research. Green Chemistry. 2014;16(2):491-515.

[15] Elliott DC, Baker EG. Catalytic hydrotreating processes for upgrading biocrude oils 1988.

[16] Elliott DC, Hart TR, Neuenschwander GG, Rotness LJ, Zacher AH. Catalytic hydroprocessing of biomass fast pyrolysis bio-oil to produce hydrocarbon products. Environmental Progress \& Sustainable Energy. 2009;28(3):441-9.

[17] Villadsen SR, Dithmer L, Forsberg R, Becker J, Rudolf A, Iversen SB, et al. Development and Application of Chemical Analysis Methods for Investigation of Bio-Oils and Aqueous Phase from Hydrothermal Liquefaction of Biomass. Energy \& Fuels. 2012;26(11):6988-98.

[18] Anastasakis K, Ross A. Hydrothermal liquefaction of the brown macro-alga Laminaria saccharina: effect of reaction conditions on product distribution and composition. Bioresource technology. 2011;102(7):4876-83.

[19] Wu M. Investigating Grey Water Footprint for the Production of Gasoline and Diesel from Biomass via Fast Pyrolysis. In: ANL, editor. Argonne IL2013.

[20] Sudasinghe N, Dungan B, Lammers P, Albrecht K, Elliott D, Hallen R, et al. High resolution FTICR mass spectral analysis of bio-oil and residual water soluble organics produced by hydrothermal liquefaction of the marine microalga Nannochloropsis salina. Fuel. 2014;119:47-56.

[21] Panisko E, Wietsma T, Lemmon T, Albrecht K, Howe D. Characterization of the aqueous fractions from hydrotreatment and hydrothermal liquefaction of lignocellulosic feedstocks. Biomass and Bioenergy. 2015;74:162-71.

[22] Frank E, Elgowainy A, Han J, Wang Z. Life cycle comparison of hydrothermal liquefaction and lipid extraction pathways to renewable diesel from algae. Mitig Adapt Strateg Glob Change. 2013;18(1):13758.

[23] Onwudili JA, Lea-Langton AR, Ross AB, Williams PT. Catalytic hydrothermal gasification of algae for hydrogen production: composition of reaction products and potential for nutrient recycling. Bioresource technology. 2013;127:72-80. 
[24] BETO. 2013 Peer Review Report: Review Panel Summary Report and Project Results. U.S. Department of Energy; 2014.

[25] Albrecht KO, Zhu Y, Schmidt AJ, Billing JM, Hart TR, Jones SB, et al. Impact of heterotrophically stressed algae for biofuel production via hydrothermal liquefaction and catalytic hydrotreating in continuous-flow reactors. Algal Research. 2016;14:17-27.

[26] National Alliance for Advanced Biofuels and Bio-Products (NAABB), Full Final Report, Section II. 2013.

[27] Maddi B, Panisko E, Albrecht K, Howe D. Qualitative Characterization of the Aqueous Fraction from Hydrothermal Liquefaction of Algae Using 2D Gas Chromatography with Time-of-flight Mass Spectrometry. JoVE (Journal of Visualized Experiments). 2016(109):e53634-e.

[28] Gai C, Zhang Y, Chen W-T, Zhou Y, Schideman L, Zhang P, et al. Characterization of aqueous phase from the hydrothermal liquefaction of Chlorella pyrenoidosa. Bioresource Technology. 2015;184:328-35.

[29] Goldman Y, Garti N, Sasson Y, Ginzburg B-Z, Bloch MR. Conversion of halophilic algae into extractable oil. 2. Pyrolysis of proteins. Fuel. 1981;60(2):90-2.

[30] Saiz-Jimenez C. Analytical Pyrolysis of Humic Substances: Pitfalls, Limitations, and Possible Solutions. Environmental Science \& Technology. 1994;28(11):1773-80.

[31] Klee MS, Cochran J, Merrick M, Blumberg LM. Evaluation of conditions of comprehensive twodimensional gas chromatography that yield a near-theoretical maximum in peak capacity gain. Journal of Chromatography A. 2015;1383(0):151-9.

[32] Yang HP, Yan R, Chen HP, Lee DH, Zheng CG. Characteristics of hemicellulose, cellulose and lignin pyrolysis. Fuel. 2007;86(12-13):1781-8.

[33] Panisko E, Wietsma T, Lemmon T, Albrecht K, Howe D. Characterization of the aqueous fractions from hydrotreatment and hydrothermal liquefaction of lignocellulosic feedstocks. Biomass and Bioenergy. 2015;74(0):162-71. 
[34] Meng L, Burris S, Bui H, Pan W-P. Development of an Analytical Method for Distinguishing Ammonium Bicarbonate from the Products of an Aqueous Ammonia CO2 Scrubber. Analytical Chemistry. 2005;77(18):5947-52.

[35] Scriven EFV, Murugan R. Pyridine and Pyridine Derivatives. Kirk-Othmer Encyclopedia of Chemical Technology: John Wiley \& Sons, Inc.; 2000.

[36] Higashio Y, Shoji T. Heterocyclic compounds such as pyrrole, pyridines, pyrrolidine, piperidine, indole, imidazol and pyrazines. Applied Catalysis A: General. 2004;260(2):251-9.

[37] Ndaji FE, Thomas KM. The kinetics of coal solvent swelling using pyridine as solvent. Fuel. 1993;72(11):1525-30.

[38] Fillon H, Gosmini C, Nédélec J-Y, Périchon J. Electrosynthesis of functionalized organodizinc compounds from aromatic dihalides via a cobalt catalysis in acetonitrile/pyridine as solvent. Tetrahedron Letters. 2001;42(23):3843-6.

[39] Silin MA, Ivanova LV, Burov EA, Koshelev VN, Bordubanova EG. Synthesis and testing of polyalkenyl succinimides as components of detergent additives for motor fuels. Pet Chem. 2012;52(4):272-7.

[40] Bialer M. Chemical properties of antiepileptic drugs (AEDs). Advanced Drug Delivery Reviews. 2012;64(10):887-95.

[41] Bellina F, Rossi R. Synthesis and biological activity of pyrrole, pyrroline and pyrrolidine derivatives with two aryl groups on adjacent positions. Tetrahedron. 2006;62(31):7213-56.

[42] Snell RW, Shanks BH. CeMOx-Promoted Ketonization of Biomass-Derived Carboxylic Acids in the Condensed Phase. ACS Catalysis. 2014;4(2):512-8.

[43] Wang Y, Jin W, Huang T, Zhu L, Wu C, Yu G. Characteristics of Alkali and Alkaline-Earth Metals for the Catalytic Gasification of Coal Char in a Fixed-Bed Reactor. Energy Technology. 2013;1(9):54450.

[44] Lv D, Xu M, Liu X, Zhan Z, Li Z, Yao H. Effect of cellulose, lignin, alkali and alkaline earth metallic species on biomass pyrolysis and gasification. Fuel Processing Technology. 2010;91(8):903-9. 
[45] Ding N, Azargohar R, Dalai AK, Kozinski JA. Catalytic gasification of glucose to H2 in supercritical water. Fuel Processing Technology. 2014;127:33-40.

[46] Stonor MR, Ferguson TE, Chen JG, Park AHA. Biomass conversion to $\mathrm{H}_{2}$ with substantially suppressed $\mathrm{CO}_{2}$ formation in the presence of Group I \& Group II hydroxides and a $\mathrm{Ni} / \mathrm{ZrO}_{2}$ catalyst.

Energy and Environmental Science. 2015;8(6):1702-6.

[47] Cherad R, Onwudili JA, Williams PT, Ross AB. A parametric study on supercritical water gasification of Laminaria hyperborea: A carbohydrate-rich macroalga. Bioresource Technology. 2014;169:573-80. 


\begin{tabular}{|l|c|c|c|c|c|c|c|c|}
\hline \multirow{2}{*}{ Items } & \multicolumn{3}{|c|}{ Saltwater (SW) algae slurry } & \multicolumn{3}{c|}{ Freshwater (FW) algae slurry } \\
\cline { 2 - 9 } & SW1 & SW2 & SW3 & SW4 & FW1 & FW2 & FW3 & FW4 \\
\hline $\begin{array}{l}\text { Ash-free solids in } \\
\text { Feed (wt\%) }\end{array}$ & 17.8 & 18.1 & 17.0 & 17.6 & 19.4 & 13.4 & 15.9 & 18.0 \\
\hline Reactor temp ( $\left.{ }^{\circ} \mathrm{C}\right)$ & 349 & 350 & 346 & 343 & 350 & 349 & 343 & 340 \\
\hline $\begin{array}{l}\text { Reactor Pressure } \\
\text { (Mpa) }\end{array}$ & 20.3 & 20.2 & 20.9 & 20.2 & 20.5 & 20.6 & 20.1 & 20.3 \\
\hline $\begin{array}{l}\text { Space velocity } \\
(\text { L/L/h) }\end{array}$ & 2.2 & 2.2 & 2.2 & 5.1 & 2.2 & 2.2 & 1.9 & 1.9 \\
\hline Feed rate (L/h) & 1.5 & 1.5 & 1.5 & 3.0 & 1.5 & 1.5 & 2.0 & 2.0 \\
\hline $\begin{array}{l}\text { pH of aqueous } \\
\text { fraction }\end{array}$ & 7.9 & 7.9 & 7.6 & 7.9 & 3.7 & 8.3 & 8.5 & 8.8 \\
\hline $\begin{array}{l}\text { Aqueous carbon } \\
\text { yield (wt\%) }\end{array}$ & 23 & 22 & 27 & 33 & 10 & 34 & 29 & 33 \\
\hline $\begin{array}{l}\text { Chemical Oxygen } \\
\text { Demand (g/L) of } \\
\text { aqueous fraction }\end{array}$ & 55.6 & 68.4 & 43.8 & 84.9 & 44.6 & 60.8 & 63.9 & 84.8 \\
\hline
\end{tabular}


Table
\[ \begin{array}{r}\text { Table 1: Operating } \mathrm{p} \\ \text { water algal cultures. }\end{array} \] Table 1: Operating parameters used to generate the aqueous fraction from HTL of saline water and fresh
water algal cultures. Table
\[ \begin{array}{l}\text { Table 1: Operating } \mathrm{p} \\ \text { water algal cultures. }\end{array} \]

.
parameters used to generate the aqueous fraction from HTL of saline water and fresh parameters used to generate the aqueous fraction from HTL of saline water and fresh 列

(1)

water

(2)

(1) 


\begin{tabular}{|c|c|c|}
\hline Name & $\begin{array}{l}\text { RI (primary, } \\
\text { secondary) ins }\end{array}$ & Similerity \\
\hline Carbon Soxide & $222,0.300$ & 982 \\
\hline Carbsaic acid, monommmonium sait & $222,3.255$ & 999 \\
\hline Trinethylamine & $240,3.635$ & 943 \\
\hline Ethanamine, N,N-dimethyt- & $258,4.090$ & 812 \\
\hline Acetone & $354,3.755$ & 959 \\
\hline 2-Propanol, 2-methyl. & $432,3.795$ & 810 \\
\hline 2-Butancot & $444,4.195$ & 928 \\
\hline Ethanol & $474,3.510$ & 917 \\
\hline 2.Pentanone & $546,4.705$ & 845 \\
\hline 1-Propanol, 2-methyt- & 714.3 .865 & 828 \\
\hline Pyrikline & $900,4.280$ & 922 \\
\hline 1-Butanol, 3-methyl- & $912,4.085$ & 819 \\
\hline Cyclopentasone & 912,4580 & 913 \\
\hline Pyrarine & $948,4.090$ & 901 \\
\hline Pyridine, 2-methyl- & $954,4.650$ & 820 \\
\hline Pyrazine, methyl- & $1044,4,440$ & 956 \\
\hline Pyridine, 3-enethyt- & $1098,4.610$ & 877 \\
\hline Pyrazine, 2,5-dimethyl. & $1140,4.825$ & 920 \\
\hline Pyrazine, 2,6-dimethy!- & 1152.4 .785 & 896 \\
\hline Pyrazine, ethy- & $1164,4.800$ & 861 \\
\hline Pyrazine, 2,3-dinetthyl. & $1182,4,775$ & 860 \\
\hline 2.Cyclopenten-1-one, 2-methyl. & $1236,4.525$ & 937 \\
\hline Pyrazine, timethyl- & $1278,5.135$ & 903 \\
\hline Acetamide, N,N-dinethy. & $1290,4.115$ & 958 \\
\hline Acetic acid & $1344,3,275$ & 944 \\
\hline Propanoik acid & 1482.3 .345 & 923 \\
\hline 2-Cyclopenten-1-one, 3-methyl- & $1488,4.300$ & 865 \\
\hline 2-Cyclopentes-1-one, 2,3-dinethyl- & $1518,4,660$ & 795 \\
\hline Propanoic acid 2-methy. & $1524,3,410$ & $\$ 93$ \\
\hline 3-Pentenoic acid, 4-methy- & $1596,4,140$ & 867 \\
\hline Butrooic acid & $1614,3,415$ & 901 \\
\hline Acetarnide, N-ethyl- & $1614,3,675$ & 916 \\
\hline Acetaniode, N-methyl- & $1620,3.545$ & 937 \\
\hline Propanamide, N-ethyl- & $1644,3.865$ & 925 \\
\hline Butanoic acid, 3-methyl- & $1668,3,480$ & 908 \\
\hline Propanarride, N-methy. & $1668,3.695$ & 936 \\
\hline Butanoic acid, 2-methy. & $1674,3,495$ & 898 \\
\hline 2-Pymobdinone, 1-methyl. & $1716,4.200$ & 948 \\
\hline $\mathrm{N}$-(n-Propy)ocetamide & $1722,3.820$ & 719 \\
\hline Acetamide, $\mathrm{N}$-(2-methylpropyl)- & $1746,3.970$ & 859 \\
\hline 1.5-Dinethy1-2-pymolidinone & $1746,4.395$ & 771 \\
\hline 1-Ethy-2-pynolidinone & $1758,4,415$ & 913 \\
\hline Acetamide & $1794,3,370$ & 981 \\
\hline Acetamide, N-2-propenyl. & $1794,3,700$ & 777 \\
\hline Propanamide & $1854,3.470$ & 918 \\
\hline Acctamide, N-(3-methy-2-oxobutyl)- & $1896,4: 130$ & 743 \\
\hline N-(3.Methylbutyl)acetamide & $1926,4,085$ & 920 \\
\hline 2.5-Pyrrolidinedione, 1-ethyl. & $1986,4,050$ & 884 \\
\hline à-Methy-a-propylsuscinimide & $1986,4.295$ & 789 \\
\hline 2,5-Pymobífinedione, 1-ethyt- & $2010,4.015$ & 656 \\
\hline 2.5-Pyrolidinedione, 1-methyl- & $2022,3.880$ & 954 \\
\hline 2,5-Pyrrotidinedione, 1-propy4- & 2082,4220 & 852 \\
\hline 2,6-Piperidinedione, 3-ethyl- & $2106,4.460$ & 756 \\
\hline N-[2-Hydroxyethyl]succiaimide & $2112,4,370$ & 844 \\
\hline 2-Pyrolidinone & $2184,3.710$ & 965 \\
\hline 2-Piperidinone & $2304,3.890$ & 961 \\
\hline Dimhlydromannitol & $2430,3.870$ & 900 \\
\hline 3-Pyridinol, 2-methyt. & $2454,3.575$ & 900 \\
\hline Glycerin & $2472,3,420$ & 912 \\
\hline 3.Pyridinol, 6-methyt. & $2568,3,590$ & 923 \\
\hline 3-Pyridinol & $2598,3.530$ & 938 \\
\hline
\end{tabular}


Table 2: Retention time and similarity values of chemical compounds present in aqueous stream generated from HTL of SW4 algae culture. The scale of similarity value is 0-999. R.T. represents retention time of chemical compounds. Higher similarity values correspond to a closer match of the spectra obtained for that sample to that for the compound in the NIST database. 


\begin{tabular}{|c|c|c|c|c|c|c|c|c|}
\hline & SW1 & SW2 & SW3 & SW4 & FW1 & FW2 & FW3 & FW4 \\
\hline Ammonia (assay) & $0.28 \pm 0.003$ & $0.44 \pm 0.002$ & $0.39 \pm 0.006$ & $0.5 \pm 0.02$ & $\mathrm{BQL}$ & $0.64 \pm 0.006$ & $0.7 \pm 0.004$ & $0.87 \pm 0.025$ \\
\hline Acetic acid (HPLC) & $0.5234 \pm 0.0783$ & $0.4548 \pm 0.0811$ & $0.5618 \pm 0.0742$ & $0.7208 \pm 0.0647$ & $0.3927 \pm 0.036$ & $0.2802 \pm 0.033$ & $0.2704 \pm 0.0114$ & $0.2674 \pm 0.0215$ \\
\hline Propanoic acid (HPLC) & $0.1011 \pm 0.0218$ & $0.1066 \pm 0.0283$ & $0.0989 \pm 0.0231$ & $0.0929 \pm 0.0467$ & $0.0495 \pm 0.013$ & $0.1226 \pm 0.009$ & $0.0504 \pm 0.0065$ & $0.0854 \pm 0.025$ \\
\hline Butanoic acid (HPLC) & $\mathrm{BQL}(<0.05)$ & $\mathrm{BQL}(<0.05)$ & $\mathrm{BQL}(<0.05)$ & $\mathrm{BQL}(<0.05)$ & $\mathrm{BQL}(<0.05)$ & $\mathrm{BQL}(<0.05)$ & $\mathrm{BQL}(<0.05)$ & $\mathrm{BQL}(<0.05)$ \\
\hline Ethanol (1D GC) & $0.0634 \pm 0.0048$ & $0.0960 \pm 0.0165$ & $0.247 \pm 0.0236$ & $0.0911 \pm 0.0024$ & $0.1148 \pm 0.0156$ & $0.0546 \pm 0.0073$ & $0.182 \pm 0.064$ & $0.2011 \pm 0.045$ \\
\hline Acetone (1D GC) & $0.1006 \pm 0.0121$ & $0.0663 \pm 0.0178$ & $0.1223 \pm 0.0448$ & $0.0651 \pm 0.0057$ & $0.0918 \pm 0.0231$ & $0.0564 \pm 0.0092$ & $0.0733 \pm 0.0244$ & $0.0934 \pm 0.0214$ \\
\hline 2-Butanone (1D GC) & $0.0340 \pm 0.0081$ & $0.0215 \pm 0.0102$ & $0.0394 \pm 0.0142$ & $0.0267 \pm 0.0064$ & $0.0237 \pm 0.0053$ & $0.0235 \pm 0.0036$ & $0.0337 \pm 0.0096$ & $0.0577 \pm 0.009$ \\
\hline 2-pentanone (1D GC) & $0.0041 \pm 0.0006$ & $0.0021 \pm 0.0009$ & $0.0043 \pm 0.0018$ & $0.0031 \pm 0.0006$ & BDL & $0.0019 \pm 0.0002$ & $0.0036 \pm 0.001$ & $0.004 \pm 0.0004$ \\
\hline 3-Pentanone (1D GC) & $0.0019 \pm 0.0004$ & $0.0010 \pm 0.0006$ & $0.0018 \pm 0.0003$ & $0.0018 \pm 0.0007$ & BDL & $0.001 \pm 0.0003$ & $0.0021 \pm 0.0009$ & $0.004 \pm 0.0006$ \\
\hline Pyridine (1D GC) & $0.0766 \pm 0.0077$ & $0.0614 \pm 0.0160$ & $0.0977 \pm 0.0247$ & $0.0829 \pm 0.0046$ & BDL & $0.0094 \pm 0.0023$ & $0.0088 \pm 0.0007$ & $0.0230 \pm 0.0052$ \\
\hline Cyclopentanone (1D GC) & $0.0083 \pm 0.0013$ & $0.0043 \pm 0.0011$ & $0.0106 \pm 0.005$ & $0.0086 \pm 0.002$ & $0.0077 \pm 0.0008$ & $0.0057 \pm 0.0011$ & $0.0063 \pm 0.002$ & $0.027 \pm 0.0060$ \\
\hline Acetamide (1D GC) & $0.0708 \pm 0.0103$ & $0.0756 \pm 0.005$ & $0.1122 \pm 0.0216$ & $0.1663 \pm 0.0098$ & BDL & $0.1636 \pm 0.0315$ & $0.1501 \pm 0.0645$ & $0.2036 \pm 0.0417$ \\
\hline Methyl pyrazine (1D GC) & $0.0360 \pm 0.0062$ & $0.0264 \pm 0.0062$ & $0.0385 \pm 0.008$ & $0.0716 \pm 0.02$ & $0.0165 \pm 0.0037$ & $0.1289 \pm 0.0091$ & $0.0996 \pm 0.02$ & $0.0663 \pm 0.0191$ \\
\hline N-methyl acetamide (1D GC) & $0.0983 \pm 0.0061$ & $0.0991 \pm 0.009$ & $0.1400 \pm 0.0118$ & $0.1778 \pm 0.026$ & BDL & $0.0847 \pm 0.0185$ & $0.102 \pm 0.015$ & $0.1722 \pm 0.0166$ \\
\hline N,N-dimethyl acetamide (1D GC) & BDL & $0.03 \pm 0.009$ & $0.0474 \pm 0.0055$ & $0.0777 \pm 0.0157$ & BDL & BDL & BDL & $0.2576 \pm 0.0148$ \\
\hline N-ethylacetamide (1D GC) & BDL & $0.0674 \pm 0.0125$ & $0.1332 \pm 0.0164$ & $0.1459 \pm 0.032$ & BDL & $0.0932 \pm 0.0189$ & $0.1487 \pm 0.07$ & $0.0377 \pm 0.0154$ \\
\hline Dimethyl/ethyl pyrazine (1D GC) & $0.012 \pm 0.0029$ & $0.0092 \pm 0.0027$ & $0.0135 \pm 0.004$ & $0.036 \pm 0.0123$ & BDL & $0.0218 \pm 0.00405$ & $0.0126 \pm 0.005$ & $0.0144 \pm 0.0067$ \\
\hline N-butyl-acetamide (1D GC) & $0.0452 \pm 0.0043$ & $0.0424 \pm 0.005$ & $0.0723 \pm 0.0068$ & $0.1025 \pm 0.0182$ & $\mathrm{BDL}$ & & $0.106 \pm 0.0312$ & $0.1715 \pm 0.0438$ \\
\hline 2-pyrrolidinenone, methyl (1D GC) & $0.0506 \pm 0.0049$ & $0.0407 \pm 0.0053$ & $0.0441 \pm 0.0034$ & $0.0248 \pm 0.007$ & BDL & $0.0784 \pm 0.0182$ & $0.0476 \pm 0.005$ & $0.0592 \pm 0.006$ \\
\hline 2-pyrrolidinenone (1D GC) & $0.0714 \pm 0.003$ & $0.0479 \pm 0.0057$ & $0.1145 \pm 0.009$ & $0.095 \pm 0.0151$ & BDL & $0.3776 \pm 0.0726$ & $0.21 \pm 0.09$ & $0.2931 \pm 0.0336$ \\
\hline N-methyl succinimide (2D GC) & $0.165 \pm 0.003$ & $0.1276 \pm 0.01$ & $0.189 \pm 0.005$ & $0.175 \pm 0.0112$ & $0.0086 \pm 0.0018$ & $0.2445 \pm 0.0103$ & $0.0420 \pm 0.0137$ & $0.0633 \pm 0.0051$ \\
\hline 2-pyrrolidinenone, ethyl (1D GC) & $0.0401 \pm 0.005$ & $0.0391 \pm 0.0086$ & $0.0530 \pm 0.0032$ & $0.0398 \pm 0.005$ & BDL & $0.0756 \pm 0.0207$ & $0.0725 \pm 0.03$ & $0.1040 \pm 0.0249$ \\
\hline N-ethyl succinimide (2D GC) & $0.0139 \pm 0.0018$ & $0.0149 \pm 0.0051$ & $0.0493 \pm 0.0073$ & $0.0561 \pm 0.0041$ & BDL & $0.0322 \pm 0.0108$ & $0.0407 \pm 0.01$ & $0.081 \pm 0.0059$ \\
\hline 3-pyrindol, 6-methyl (2D GC) & $\mathrm{BDL}$ & BDL & BDL & $0.0179 \pm 0.0041$ & $0.0317 \pm 0.0052$ & $0.0471 \pm 0.0069$ & $0.0463 \pm 0.009$ & $0.0338 \pm 0.0079$ \\
\hline 3-pyrindol, 2,6-dimethyl (2D GC) & BDL & BDL & $\mathrm{BDL}$ & $\mathrm{BDL}$ & $0.0211 \pm 0.004$ & & $0.0192 \pm 0.0032$ & \\
\hline 2-piperidinone (1D GC) & $0.0831 \pm 0.004$ & $0.0608 \pm 0.0069$ & $0.1107 \pm 0.01$ & $0.0800 \pm 0.015$ & BDL & $0.0787 \pm 0.01389$ & $0.0566 \pm 0.023$ & $0.0736 \pm 0.0063$ \\
\hline$\alpha$-methyl- $\alpha$-propyl succinimide (2D GC) & $0.0194 \pm 0.0014$ & $0.0122 \pm 0.0017$ & $0.0216 \pm 0.0009$ & $0.0173 \pm 0.0053$ & $\mathrm{BDL}$ & $0.0186 \pm 0.0022$ & $0.0245 \pm 0.01$ & $0.0232 \pm 0.0083$ \\
\hline 1-butyl-2-pyrrolidinone (1D GC) & $\mathrm{BDL}$ & BDL & $\mathrm{BDL}$ & $\mathrm{BDL}$ & $\mathrm{BDL}$ & $0.0119 \pm 0.0019$ & BDL & BDL \\
\hline N-(hydroxyethyl) succinimide (1D GC) & BDL & BDL & $0.0245 \pm 0.0031$ & $0.0324 \pm 0.0025$ & BDL & $0.019 \pm 0.0025$ & $0.0236 \pm 0.0065$ & $0.0284 \pm 0.0065$ \\
\hline
\end{tabular}


Table 3: Concentration, in weight percent, of major organic constituents identified in the aqueous fraction generated from HTL of saline water and fresh water algal cultures. Mean value $\pm 2 *$ standard deviation are shown. Some compounds are below quantification limit (BQL) and below detection limit (BDL).

Chemical compounds that are seen in 2D GC-TOF-MS and that were not observed in conventional GC chromatogram are marked as BDL. 


\begin{tabular}{lcccccccc}
\hline & SW1 & SW2 & SW3 & SW4 & FW1 & FW2 & FW3 & FW4 \\
\hline Chloride & 1.18 & 1.70 & 1.21 & 1.40 & 0.004 & 0.014 & 0.104 & 0.039 \\
Bromide & 0.004 & 0.006 & 0.004 & 0.005 & BDL & BDL & BDL & BDL \\
Sulfate & 0.019 & 0.027 & 0.016 & 0.020 & 0.051 & 0.031 & 0.04 & 0.054 \\
Phosphate & BDL & BDL & BDL & BDL & 0.521 & 0.687 & 0.044 & 0.177 \\
\hline
\end{tabular}

BDL - below detection limit. 
Table 4: Anion content in weight percent of the aqueous fractions generated from hydrothermal liquefaction of saline water (SW) and fresh water (FW) algal cultures measured using Ion chromatography. All the reported values are single measurements. 


\begin{tabular}{lllllllll}
\hline & SW1 & SW2 & SW3 & SW4 & FW1 & FW2 & FW3 & FW4 \\
\hline $\mathrm{Al}$ & $<0.00015$ & $<0.00015$ & 0.00017 & $<0.00015$ & 0.00017 & $<0.00015$ & $<0.00015$ & $<0.00015$ \\
$\mathrm{Ca}$ & 0.00053 & 0.00119 & 0.00085 & 0.00096 & 0.00023 & $<0.00008$ & $<0.00008$ & $<0.00008$ \\
$\mathrm{~K}$ & 0.303 & 0.276 & 0.334 & 0.370 & 0.183 & $<0.00008$ & 0.137 & 0.169 \\
$\mathrm{Mg}$ & 0.004 & 0.005 & 0.006 & 0.008 & 0.0006 & $<0.00008$ & $<0.00008$ & $<0.00008$ \\
$\mathrm{Na}$ & 0.789 & 1.117 & 0.813 & 0.918 & 0.058 & 0.018 & 0.082 & 0.015 \\
$\mathrm{P}$ & $<0.00015$ & $<0.00015$ & $<0.00015$ & $<0.00015$ & 0.164 & 0.216 & 0.017 & 0.071 \\
$\mathrm{Sr}$ & 0.0006 & 0.0009 & 0.0009 & 0.0009 & 0.0003 & 0.0002 & $<0.0001$ & $<0.0001$ \\
$\mathrm{~V}$ & $<0.00008$ & $<0.00008$ & 0.0002 & $<0.00008$ & $<0.00008$ & $<0.00008$ & $<0.00008$ & $<0.00008$ \\
$\mathrm{Si}$ & 0.0027 & 0.0017 & 0.0019 & 0.0026 & 0.0105 & 0.0081 & 0.0073 & 0.009 \\
$\mathrm{~S}$ & 0.052 & 0.044 & 0.068 & 0.088 & 0.018 & 0.018 & 0.033 & 0.040 \\
\hline
\end{tabular}




\section{Table 5 Caption}

Table 5: Cation content in weight percent of the aqueous fractions generated from hydrothermal liquefaction of saline water (SW) and fresh water (FW) algal cultures measured using ICP-OES analysis. Standard deviation was $<5 \%$ for all reported values. 


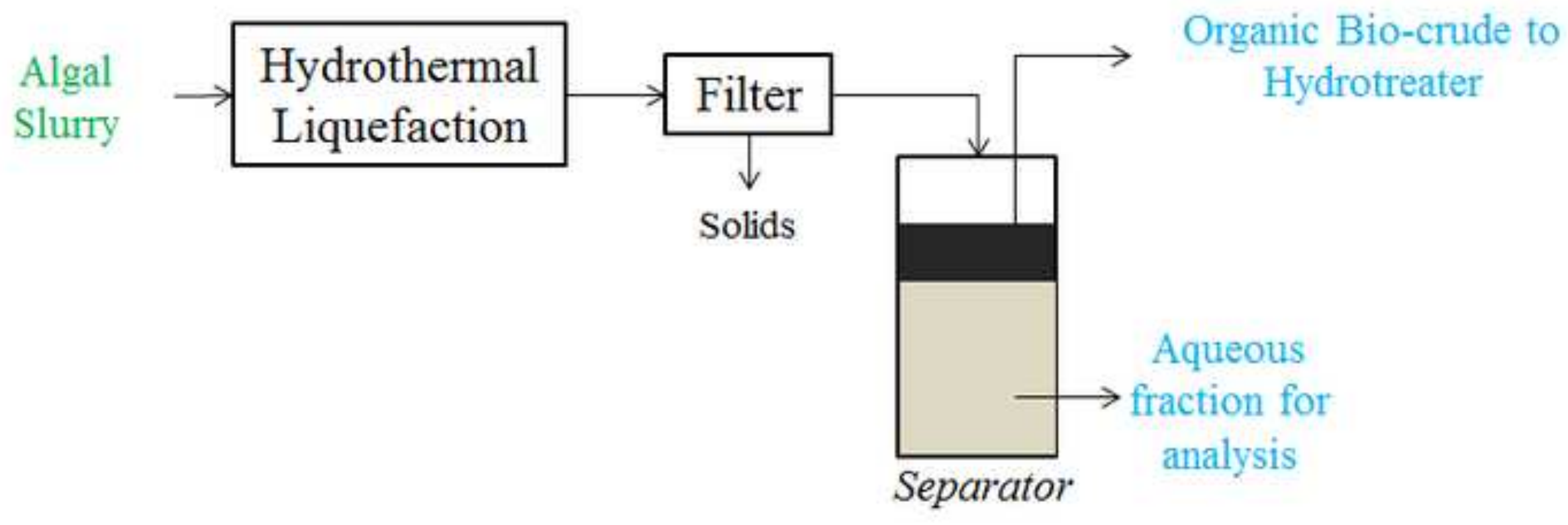


Figure 1 Caption
\[ \begin{array}{l}\text { Figure 1: Schematic flow diagram of the hydrothermal liquefaction process. Samples for analysis are } \\ \text { generated after separation of residue solids as well as organic bio-crude. }\end{array} \] Figure 1 Caption
\[ \begin{array}{l}\text { Figure 1: Schematic flow diagram of the hydrothermal liquefaction process. Samples for analysis are } \\ \text { generated after separation of residue solids as well as organic bio-crude. }\end{array} \]

Figure 1 Caption
\[ \begin{array}{l}\text { Figure 1: Schematic flow diagram of the hydrothermal liquefaction pro } \\ \text { generated after separation of residue solids as well as organic bio-crude }\end{array} \]

generated after separation of residue solids as well as organic bio-crude.
natic flow diagram of the hydrothermal liquefaction process. Samples for analysis are
matic flow diagram of the hydrothermal liquefaction process. Samples for analysis are
separation of residue solids as well as organic bio-crude.

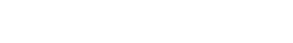

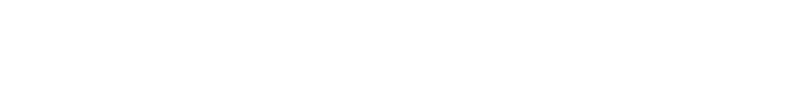
(1)

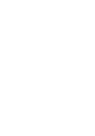
(1) samples ar (1) (1) (1) (1) .

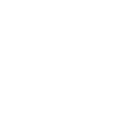
(1)

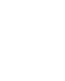
, . . (1)

$x^{2}$
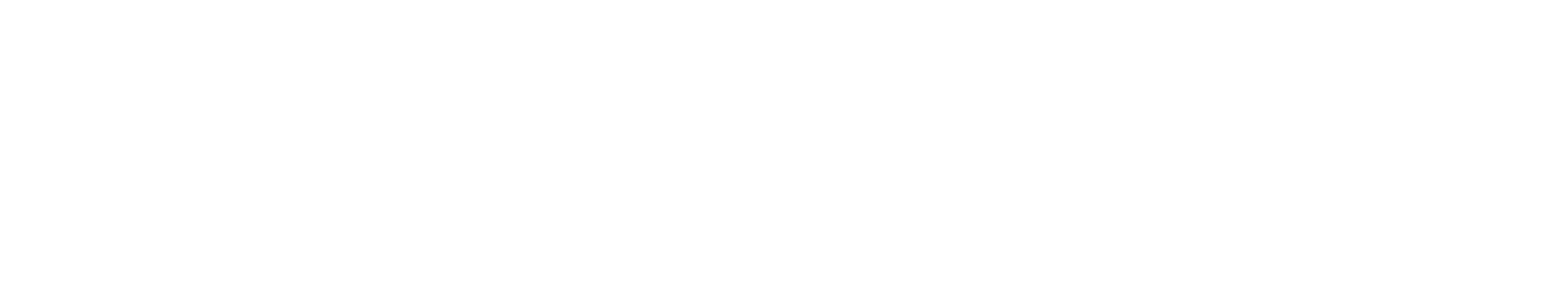


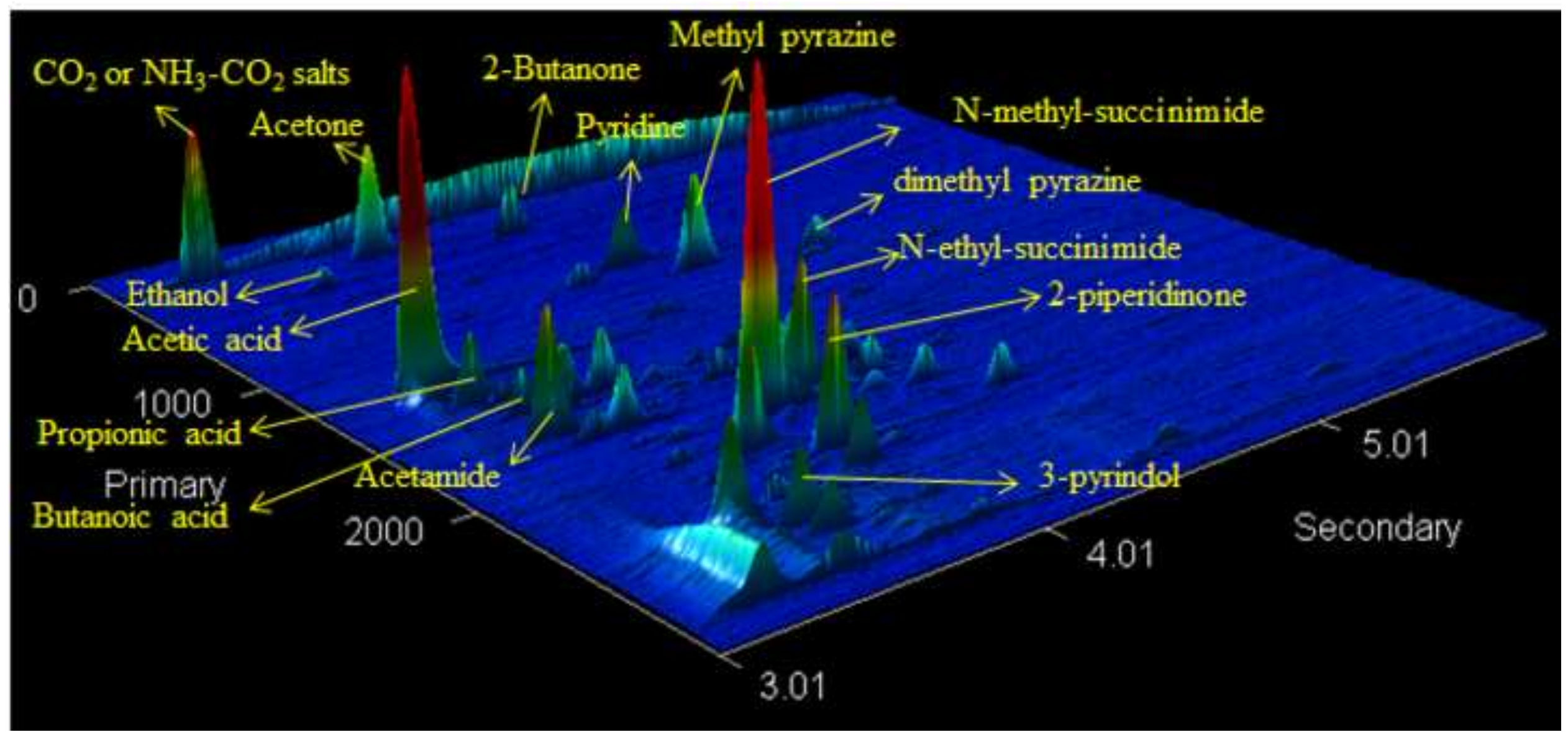


Figure 2 Caption
\[ \begin{aligned} \text { Figure 2: Three-dimensional plot of the aqueous } \\ \text { units of primary and secondary axis are seconds. } \\ \text { full list of chemical compounds, refer to Table } 2 .\end{aligned} \]

Figure 2: Three-dimensional plot of the aqueous fraction generated from HTL of SW4 algal culture. The units of primary and secondary axis are seconds. Some chemical compounds are marked in the figure. For

Figure 2 Caption
\[ \begin{array}{l}\text { Figure 2: Three-dimensional plot of the aqueous } \mathrm{f} \\ \text { units of primary and secondary axis are seconds. } \\ \text { full list of chemical compounds, refer to Table } 2 .\end{array} \] 


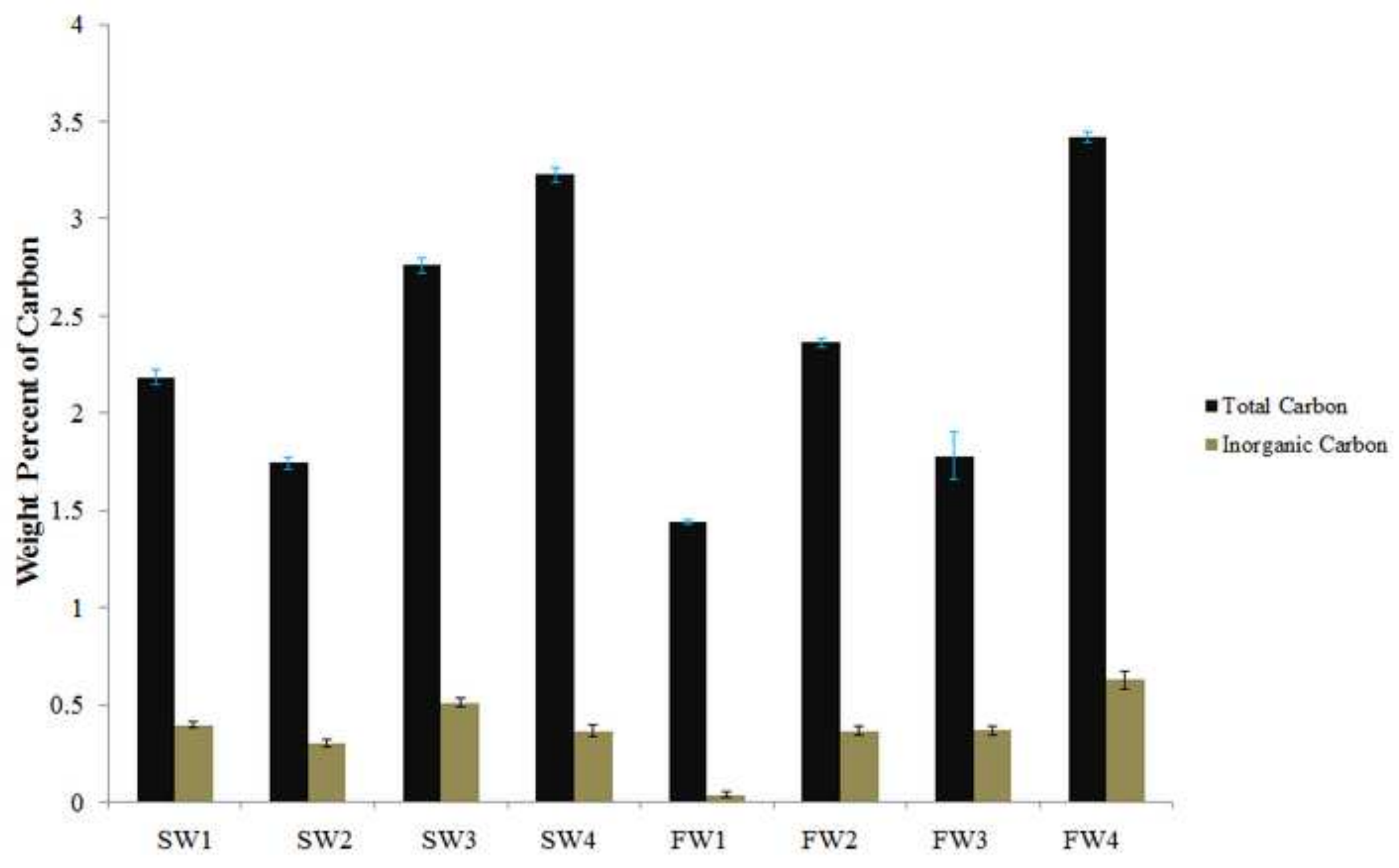


Figure 3 caption
\[ \begin{array}{l}\text { Figure } 3: \text { Total carbon content (which includes both organic and inorganic carbon; black color bars) and } \\ \text { inorganic carbon content (tan color bars) of the aqueous fractions generated from hydrothermal }\end{array} \]

Figure 3 caption
\[ \begin{array}{l}\text { Figure 3: Total carbon content (which includes both organic and inorganic carbon; black color bars) and } \\ \text { inorganic carbon content (tan color bars) of the aqueous fractions generated from hydrothermal }\end{array} \]

Figure 3 caption
\[ \begin{array}{l}\text { Figure 3: Total carbon content (which includes both organic and inorganic carbon; black color bars) and } \\ \text { inorganic carbon content (tan color bars) of the aqueous fractions generated from hydrothermal } \\ \text { liquefaction of saline water (SW) and fresh water (FW) algal cultures. }\end{array} \]

inorganic carbon content (tan color bars) of the aqueous fractions generated from hydrothermal
liquefaction of saline water (SW) and fresh water (FW) algal cultures.

liquefaction of saline water (SW) and fresh water (FW) algal cultures.

Figure 3 caption
\[ \begin{array}{l}\text { Figure 3: Total carbon content (which includes both organic and inorganic carbon; black color bars) and } \\ \text { inorganic carbon content (tan color bars) of the aqueous fractions generated from hydrothermal }\end{array} \]

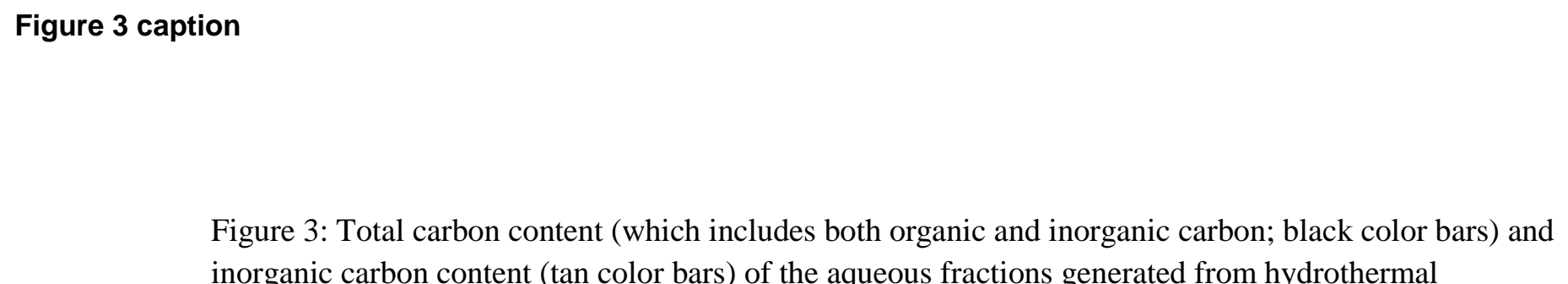

-

(1)

(1)

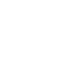

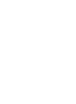
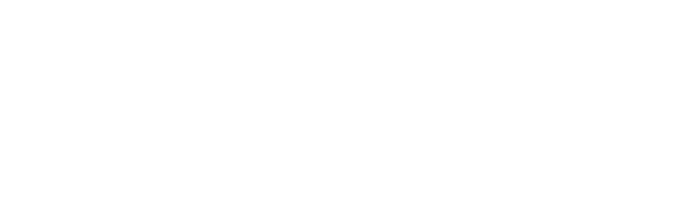

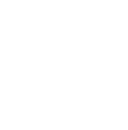
$=$

(1)

(1)
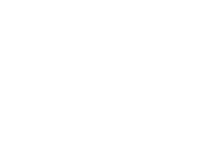


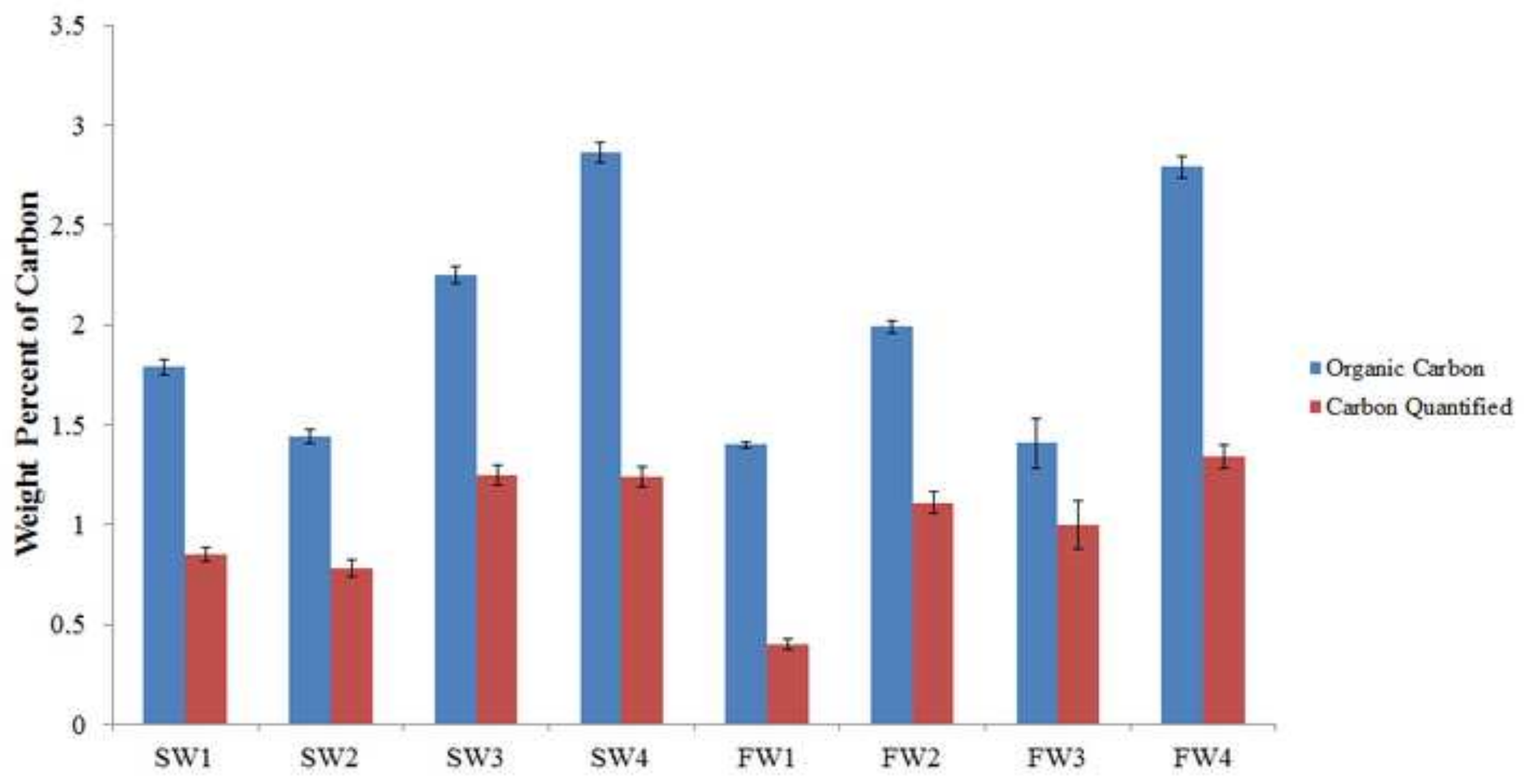


Figure 4: Total organic carbon (blue color bars; calculated by subtracting total inorganic carbon from total carbon) and quantified carbon (red color bars) of the aqueous fractions generated from hydrothermal

liquefaction of saline water (SW) and fresh water (FW) algal cultures.

Figure 4 caption 


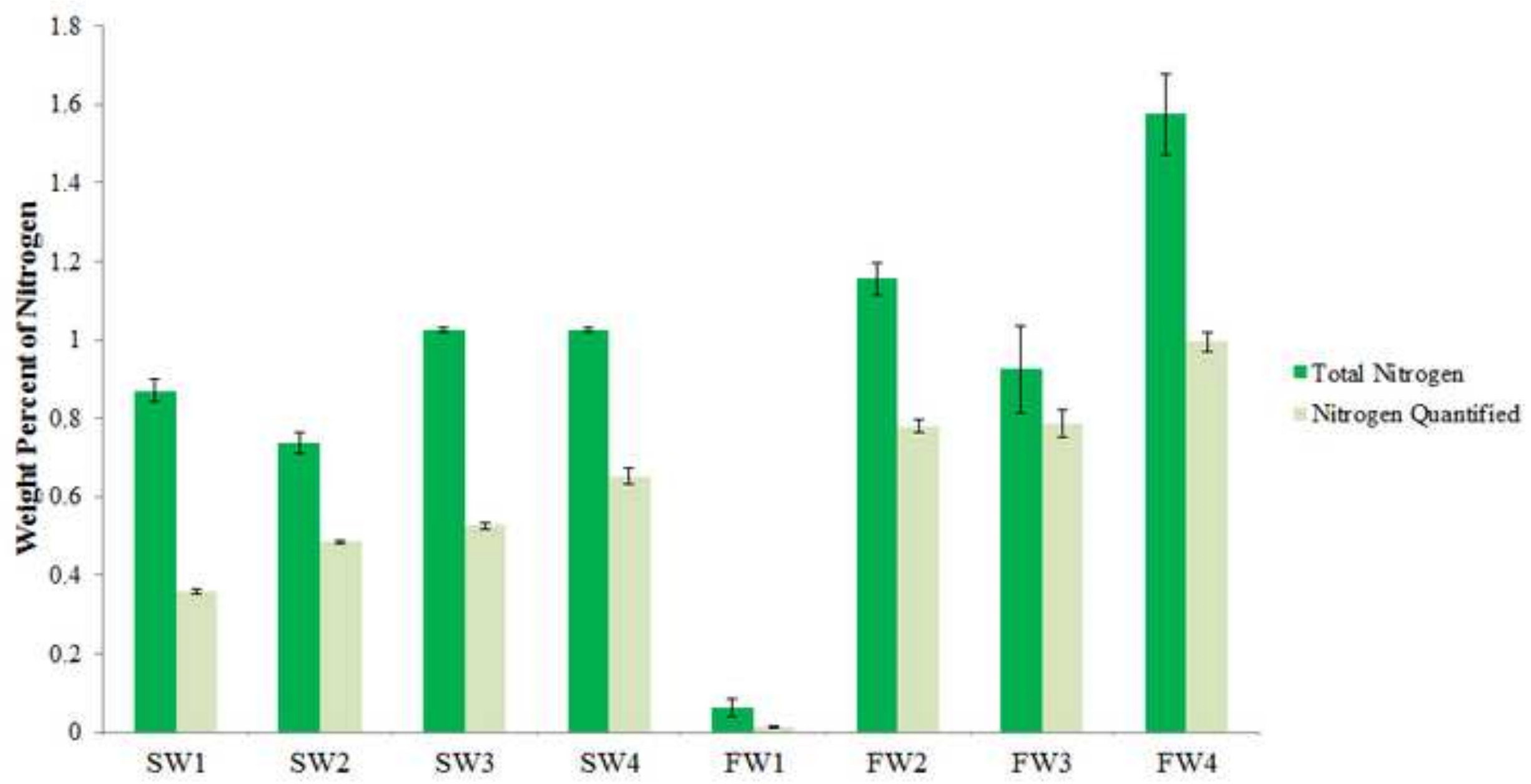


Figure 5: Total nitrogen (green color bars) and quantified nitrogen (light blue color bars) of the aqueous

fractions generated from hydrothermal liquefaction of saline water (SW) and fresh water (FW) algal cultures.

\section{Figure 5 caption}

